\title{
Review
}

\section{Is there a Neurobiological Rationale for the Utility of the Iowa Gambling Task in Parkinson's Disease?}

\author{
Michael F. Salvatore ${ }^{\mathrm{a}}$, Isabel Soto ${ }^{\mathrm{a}}$, Helene Alphonso ${ }^{\mathrm{b}}$, Rebecca Cunningham ${ }^{\mathrm{c}}$, \\ Rachael James $^{\mathrm{a}}$ and Vicki A. Nejtek ${ }^{\mathrm{a}, *}$ \\ a Institute for Healthy Aging, University of North Texas Health Science Center, Fort Worth, TX, USA \\ ${ }^{\mathrm{b}}$ John Peter Smith Health Network, University of North Texas Health Science Center, Fort Worth, TX, USA \\ ${ }^{\mathrm{c} C o l l e g e}$ of Pharmacy, University of North Texas Health Science Center, Fort Worth, TX, USA
}

\begin{abstract}
Up to 23\% of newly diagnosed, non-demented, Parkinson's disease (PD) patients experience deficits in executive functioning (EF). In fact, EF deficits may occur up to 39-months prior to the onset of motor decline. Optimal EF requires working memory, attention, cognitive flexibility, and response inhibition underlying appropriate decision-making. The capacity for making strategic decisions requires inhibiting imprudent decisions and are associated with noradrenergic and dopaminergic signaling in prefrontal and orbitofrontal cortex. Catecholaminergic dysfunction and the loss of noradrenergic and dopaminergic cell bodies early in PD progression in the aforementioned cortical areas likely contribute to EF deficits resulting in non-strategic decision-making. Thus, detecting these deficits early in the disease process could help identify a significant portion of individuals with PD pathology (14-60\%) before frank motor impairment. A task to evaluate EF in the domain of non-strategic decision-making might be useful to indicate the moderate loss of catecholamines that occurs early in PD pathology prior to motor decline and cognitive impairment. In this review, we focus on the potential utility of the Iowa Gambling Task (IGT) for this purpose, given significant overlap between in loss of dopaminergic and noradrenergic cells bodies in early PD and the deficits in catecholamine function associated with decreased EF. As such, given the loss of catecholamines already well-underway after PD diagnosis, we evaluate the potential utility of the IGT to identify the risk of therapeutic non-compliance and a potential companion approach to detect PD in premotor stages.
\end{abstract}

Keywords: Iowa gambling task, Parkinson's disease, therapeutic compliance, decision-making

\section{BACKGROUND}

Parkinson's disease (PD) is a debilitating neurodegenerative disease whose projected prevalence in the US is expected to rise to over one million people by

\footnotetext{
${ }^{*}$ Correspondence to: Vicki A. Nejtek, PhD, Institute for Healthy Aging, University of North Texas Health Science Center, Fort Worth, TX, 76107, USA. Tel.: +1 817735 0640; E-mail: vicki.nejtek@unthsc.edu.
}

2030 [1]. While PD is known for progressive motor deterioration, it also produces non-motor symptoms (NMS) [2]. These NMS can also be progressive in severity, and yet the neurobiological basis of these NMS remain under-investigated. Findings from the 2016 Parkinson's Disease Foundation Community Choice Research Award Program indicate that up to $50 \%$ of non-demented PD patients have some type of cognitive problems [3]. Some data suggest 
that executive functioning (EF) impairments, such as memory problems, non-strategic decision-making, inattention, and decreased cognitive flexibility occur in up to $\sim 24 \%$ of drug naive individuals in the prodromal pre-motor phase of PD [4]. Similarly, Durcan et al. (2019) found 36\% of PD patients experienced memory and attention problems approximately 39-months prior to motor symptom onset [5]. Anywhere from $4 \%-60 \%$ of PD patients (medicated and de-novo patients alike) reportedly experience some type of cognitive dysfunction described here as nonstrategic decision-making [6-11].

Recognizing non-strategic (i.e., careless or disadvantageous) decision-making as a cognitive marker among other non-motor phenotypes (e.g., hyposmia, constipation, REM disorder, etc.) may be another way to identify a subset of individuals at-risk for PD prior to motor decline. Without a diagnosis of $\mathrm{PD}$, a test to measure subtle impairments in decisionmaking might be useful in identifying those at-risk for an eventual PD diagnosis. For example, cognitive functioning, therapeutic compliance, and disease resilience are intricately woven together to affect overall quality of life [12-15]. Once a PD diagnosis has been made after motor decline, it is essential for patients to adhere to medication regimens. Unfortunately, compliance can be a problem for many PD patients when their regimen is complex and confusing [12]. If non-strategic decision-making could be identified prior to a PD diagnosis or even with the earliest indication of some motor decline, then clinicians might have an opportunity to intervene earlier in the management and education of health- and therapeutic-related risks. Earlier recognition during PD progression could increase the patient's and caregiver's chances for the best quality of life possible.

An objective, emotionally salient, and well-known test measuring decision-making in PD populations is the Iowa Gambling Task (IGT) [16-23]. This is just one of several neurocognitive tests that might be used to evaluate decision-making in relation to cognitive flexibility and response inhibition. Here, however, we examine the IGT for its potential to identify problems with decision-making that could signal the onset of at-risk behaviors leading to therapeutic non-compliance. In fact, in other populations the IGT has been identified as a predictive tool for problematic health behaviors. For example, Nejtek et al. (2013) [24] found that a single baseline IGT score predicted future negative behaviors within 4-weeks after testing. Specifically, in a population known to make non-strategic decisions (i.e., comorbid bipolar and substance use), Nejtek and colleagues (2013) [24] showed that the IGT predicted future relapse even after 8- to 19-weeks of abstinence and scores were not influenced by dopaminergic medication effects. Moreover, non-strategic decision-making was evident, as net losses were based on emotional-salience and the overriding thrill of winning rather than strategy [24]. Although there are several clinical investigations of the IGT in various stages of PD, the results are mixed; and to our knowledge, the IGT has not been characterized as a possible tool to predict therapeutic non-compliance nor the possibility of PD prior to clinical diagnosis.

Here, we also summarize the current neurobiological evidence that deficient catecholamine function or signaling can influence cognitive domains that lead to non-strategic decision-making which can be interrogated by the IGT [16-24]. We point out that given the loss of these same catecholamine neuron populations, beginning early in PD and being progressive in nature, there is strong plausible neurobiological basis to expect that deficits in EF, specifically decisionmaking in those at-risk for PD, could be evaluated with the IGT. We discuss what the outcomes of IGT use in the PD literature are in the context of deficient catecholamine signaling, and how this may bring new opportunities to increase our understanding about the possible applicability of the IGT in relation to the issue of therapeutic noncompliance. Given that PD risk is greater in males, we also examine the possibilities and pitfalls of using the IGT to explain evidence for differences in non-strategic decisionmaking between men and women and how this may be applicable, or not, in the context of PD.

\section{Brief overview of the IGT}

The IGT was originally developed as a clinical research tool, to assess cognitive flexibility associated with real-world decision-making in patients with neurodegenerative disease secondary to ventromedial prefrontal cortex (PFC) lesions [16-18]. Over time, accumulating evidence indicated that the IGT also activated the orbitofrontal cortex (OFC) and the amygdala involved with emotionally-salient decision-making associated with response inhibition and perceptions of rewards versus punishments [19-23]. Since its inception, the IGT has been a reliable approach in examining the influence of emotionally salient reward-based risk-taking on making decisions that invariably lead to negative consequences [16-24]. 
Participants are instructed to consecutively choose cards from four different decks that are assigned a monetary gain or loss over the course of 100 trials. The goal is to win as much money as possible. Unbeknownst to the participant, two of the four decks are preset to pair low dollar winning cards with more frequent high dollar losing cards. Cards in two of the decks have higher monetary gains and will generate losses greater than that of the amount gained, whereas cards in the two other decks will have less monetary gain and will also have equal losses. Over the course of 100 trials, the goal is to have a positive net dollar amount at the end of the task. Thus, a player must show cognitive flexibility in their learning ability that will enable them to adopt a strategy to avoid the card decks that most often result in higher dollar losses while figuring out that the low winning cards ultimately result in a positive net gain over time.

A player with an intact OFC, amygdala, and PFC will learn over the course of 100 trials to adopt a decisional strategy to avoid the card decks that yield high dollar wins paired with higher dollar losses. Gaining a net profit at the end of the task requires response inhibition and strategic decision-making. This is something that is difficult for risk-takers and those who have neuropathology in the aforementioned brain structures, even after given multiple test-taking opportunities [21, 24]. The IGT has also been shown to predict disease trajectories such as substance relapse in psychiatric disorders associated with inherent dopaminergic dysfunction [24]. Importantly, this vulnerability was present, independent of the subjects' positive response to antipsychotics [24]. Taken together, these data suggest that the IGT has potential to reveal an individual's propensity towards making non-strategic decision-making, and may be used in clinically-based evaluations.

\section{WHAT NEURAL AREAS AND MECHANISMS OF PD ARE PROBED BY THE IGT?}

In addition to the OFC and PFC areas that are activated in the process of reward-based decision-making that could be measured by the IGT in humans, the ventral striatum has also been implicated in decisions involving risk and reward in animal PD models $[18-20,25,26]$. These regions are innervated by noradrenergic terminals originating from the locus ceruleus (LC) [27, 28], dopaminergic terminals originating from the substantia nigra (pars compacta
SNc), and the ventral tegmental area (VTA) [29-31]. Deficits in norepinephrine (NE) and dopamine (DA) signaling in these three key areas have been identified as contributors to deficits in domains of $\mathrm{EF}$ that lead to non-strategic, disadvantageous decisionmaking [29-38].

Emerging animal PD models and clinical PD studies clearly show loss of these three catecholaminergic neuronal populations contributing to disease symptom characteristics $[39,40]$. Conceivably, the neural loss in PD constitutes a composite neurobiological signature that is associated with non-strategic decision-making. Taken together, the IGT might be an additional diagnostic tool in the clinical armamentarium to identify problems in strategic decision-making in those who might be at-risk for PD or therapeutic non-compliance.

So far, there is substantial evidence showing that normal dopaminergic and noradrenergic function is necessary for advantageous, strategic decisionmaking. Animal models employ lesioning techniques, direct circuit modulation, or pharmacological interrogations to assess behaviors, making them highly valuable to disentangle the neuronal pathways and neurotransmitter signaling involved in decisionmaking. As such, evaluating the neurobiological basis of decision-making strategies and outcomes in animal models should employ behavioral methods that have face validity in comparison to human studies [30, 41, 42]. Given the evidence that deficits in dopaminergic and noradrenergic signaling impair advantageous and strategic decision-making, the question arises as to whether these deficits could also be interrogated in PD patients with the IGT. If so, when does DA and NE loss in PD arise to a magnitude sufficient to impair decision-making that could be detected by the IGT, particularly in the preclinical, prodromal, or early stages of PD? Evidence of impaired decisionmaking prior to a PD diagnosis or onset of motor decline could, at the very least, signal the need to initiate interventions to slow PD progression, particularly if other reliable biomarkers or phenotypes of PD are present.

The primary neuropathological basis for impaired motor function in PD is nigrostriatal DA neuron loss. It is well-established that the loss of DA markers in the nigrostriatal terminals in the striatum must reach near $80 \%$ prior to the onset of motor impairment [43-45]. Prior to this remarkable magnitude of nigrostriatal DA loss, it is conceivable that less than 80\% nigrostriatal DA loss may impair EF components, if nigrostriatal DA also subserves a component 
of executive functioning (EF) related to decisionmaking. In fact, nigrostriatal DA function does affect context-related reward or visual stimuli related to working memory, given recent evidence of its innervation of the PFC $[31,35,36]$. Thus, it is plausible that some level of nigrostriatal DA loss will diminish DA signaling in the PFC, thereby influencing components of EF and specifically decision-making [35, 36]. In fact, PD animal model results support this possibility, as loss of DA to levels less than necessary for motor impairment adversely impact responsivity to salient cues or reversal learning [26, 33]. Therefore, loss of nigrostriatal neurons in the prodromal or early stages of PD could play a pivotal role in facilitating EF deficits adversely affecting decision-making before dopamine replacement therapy has been initiated.

Until recently, it was thought that PD pathology largely affected only the nigrostriatal DA neurons and spared the more medially-located DA neurons of the VTA. However, more recent evidence clearly shows loss of DA innervation originating from the VTA [46, 47], ranging from 40-77\%. Our understanding of how DA loss from the VTA affects EF related to decisionmaking centers upon the clear evidence that efferent projections from the VTA innervate regions involved with EF, including nucleus accumbens, amygdala (AMY), and medial PFC, wherein DA has profound influence on physiological function of neuronal circuits therein [34-36]. In particular, DA function in the PFC plays a major role in goal-directed behaviors requiring strategic decision-making. For example, interpreting the relevance of stimuli in the decisionmaking process, controlling spontaneous impulses to act without foresight, and deciding whether or not to engage in a goal-directed response is subserved by DA function in the PFC [30, 35, 48]. Moreover, if the stimuli had any sort of emotional tone, for example obtaining a reward, then the OFC and AMY would also be involved.

Animal models suggest that loss of DA in cortical regions, arising from PD-related loss of these neurons from the VTA, would impair EF involved in strategic decision-making and could therefore lead to outcomes that are ultimately disadvantageous. In the context of PD progression, loss of DA in the VTA is detected within 2 years of PD diagnosis (Hoehn Yahr stage 1-2), and at least according to a recent human imaging study, this loss is comparable to that in the SN during that time [47]. Since DA loss is greater in the terminal regions in ventral striatum (more than twice the effect size between PD and control) than the VTA itself at this time point [47], it is conceivable that
DA loss would be similar in other VTA efferent targets, notably the PFC. As such, the loss of DA from the VTA could affect the PD patient's ability at the early stage or even prodromal phase to discern stimuli that are particularly relevant for advantageous outcomes versus stimuli leading to negative outcomes. From the perspective of using the IGT, persons with or at-risk for PD may therefore demonstrate a diminished ability to inhibit poor choices by choosing cards that are not associated with an advantageous, longterm gain arising, in part, from early stages of VTA neuron loss.

The locus ceruleus is the only source of NE efferents that project to brain areas in decision-making; the prefrontal cortex $[27,28]$. The LC can also be divided into subpopulations [49]. While it is not clear whether certain subpopulations of LC neurons are affected in PD, very recent evidence shows definitive LC loss early in the disease process [50-52]. Based upon the evidence that EF is affected in $30-40 \%$ of early stage or prodromal PD [4, 5], it is very likely that PD pathology involves LC subpopulations subserving EF. In fact, the magnitude of LC neuron loss in de novo PD (Hoehn and Yahr stage 1-2) correlates to the severity of EF impairment [50]. The loss of LC neurons in early stage PD may even contribute in nigrostriatal neuron loss $[53,54]$. Thus, deficits in EF or decision-making may arise from the loss of LC neurons themselves or the impact of their loss on nigrostriatal neurons early in the disease process.

Advantageous outcomes in decision-making in goal-oriented behavior require attention shift and memory retrieval needed for response inhibition and LC neuron function affects these cognitive domains needed to assign significance to a stimulus $[32,55,56]$. This optimizes behavioral performance and adaptions in decision-making necessary during changing or ambiguous environmental cues [27, 37, 38]. Given the evidence for LC neuron loss and EF-related impairments early in PD [50], examining the behavioral impact of LC lesion in animal models could reveal whether similar deficits in EF arise. Early work indicated that NE loss in the cortex impaired behavior related to selective attention and arousal [56]. Many years later, work in early stage PD shows that mild impairment in cognitive flexibility correlates with loss of LC neurons [50]. Thus, improving NE signaling in the cortical regions would be expected to improve EF. In fact, blocking NE uptake with atomoxetine in rat and primate models augments NE function, and improves attention 
in orienting to context-specific tasks and response inhibition [57, 58]. In PD patients at mild-tomoderate stage (Hoehn and Yahr 2,3), atomoxetine improved tasks related to response inhibition and did so with increased functionality of relevant cortical areas [59]. In summary, very recent evidence in the early to mid-stage PD patient indicates that the loss of LC neurons may impairs EF underlying response disinhibition and non-strategic decision-making. In substantiating a role for NE function in EF, the IGT could be useful to identify those at-risk for PD in the preclinical phase, and those in a very early or prodromal phase of PD, particularly if used in combination with other indications of established indices of risk phenotype (to be discussed in brief below).

In conclusion, animal models clearly show that impairments in NE or DA function in the PFC and OFC are associated with EF deficits that contribute to disadvantageous decision-making. Loss of dopaminergic and noradrenergic cell bodies in the $\mathrm{SN}$, VTA, and LC occurs in PD, and more recent evidence substantiates loss of each neuronal population in early stage PD. Such loss could impair EF domains related to decision-making in early stage $\mathrm{PD}$, which is now recently reported in prodromal PD $[4,5]$. Although significant progress has been made in identifying risk factors that strongly predict PD in the prodromal phase, a firm diagnosis of PD currently requires the onset of motor impairment - at which point substantial loss of these neuron populations has already occurred. Given the recent evidence that specific populations of nigrostriatal neurons target the PFC, it is plausible that their loss could also adversely affect EF (and thus possibly detected) prior to onset of motor impairment, although notably the metric for the magnitude of loss of these specific populations required for $\mathrm{EF}$ deficits has not been established, as it has for the onset of motor impairment $[44,45]$. We therefore propose that an additional measure to help establish the criteria for identifying pre-motor symptoms related to the loss of these neurons might be to substantiate impairments to decision-making. Figure 1 illustrates the progressive loss of the aforementioned neuronal populations resulting in DA and NE signaling deficits in the cortical regions with the expected impact upon specific domains of EF affecting decision-making that may be measured with the IGT. In combination with other markers of PD, exploring the applicability of the IGT may help detect problematic decision-making before frank motor impairment, which is tied to loss of DA and NE neurons.

\section{CLINICAL LITERATURE SEARCH}

The online database Scopus was used to identify relevant studies using the year of publication range 1999-2019. A flow diagram shows search and inclusion/exclusion criteria (Fig. 2). Searching for 'Parkinson's disease' yielded 117,136 results, using the key term 'Iowa Gambling Task' resulted in 1,267 results and we found 97 studies using the search term 'Bechara Gambling Task'. When 'Iowa Gambling Task' AND 'Parkinson's disease' were combined, we found 47 results and when changing the combination to 'Bechara Gambling Task' AND 'Parkinson's disease' we found 1 result. Case reports, conference abstracts, group sizes of less than 10, and those specifically examining Pathological Gambling as an Impulse Control Disorder were excluded. From this, 17 studies met our search criteria that focused on decision-making in PD patients using the IGT. We found no PD studies using the IGT to predict therapeutic compliance.

\section{IS THERE A ROLE FOR USING THE IGT TO PREDICT THERAPEUTIC COMPLIANCE IN PD?}

Roughly $17 \%$ of PD patients have problems with response inhibition $[60,61]$, which is likely to be associated with deficient catecholamine signaling in the cortical regions subserving decision-making, as suggested by previous studies $[29,30,36,39,46$, $47,52,55,58,59]$. Therapeutic non-compliance is a major issue in the PD patient, as only $3-10 \%$ of PD patients adhere to multiple dosing intervals inherent in DRT regimens [12, 61]. With five or more years of multiple dosing regimens, compliance drops to roughly $3 \%$ with up to $70 \%$ of PD patients self-discontinuing DA therapy $[12,61]$. Moreover, these PD patients have an increased risk for life-threatening complications such as malignant syndrome or parkinsonism-hyperpyrexia syndrome (similar to neuroleptic malignant syndrome) with mortality rates up to 4\% [62]. Arguably, the decision to self-discontinue or modify a therapeutic regimen may be related to the inability to foresee or learn from the adverse consequences thereof. Therefore, approaches to parse out the patient's potential inability to weigh the consequences of this decision are critically important. At present, no prospective study in PD patients with adequate controls for disease duration and medication history exists to show whether or not the IGT could possibly identify 


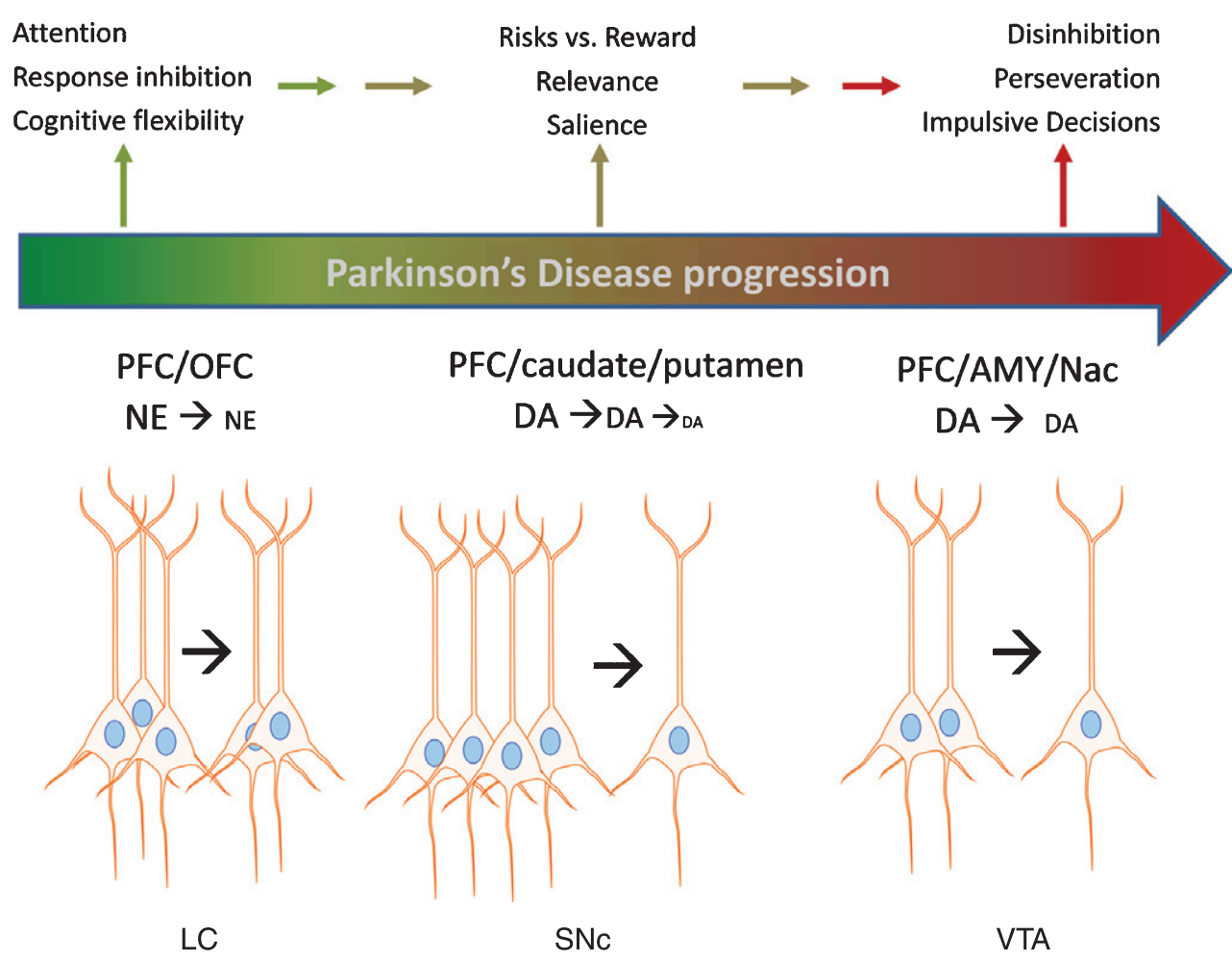

Fig. 1. Impact of catecholamine cell body loss in Parkinson's disease on noradrenergic and dopaminergic signaling in cortical and subcortical regions and executive functions. A schematic of Parkinson's progression is presented by the arrow, wherein intact functions (green color) in executive function (EF) are subserved by an intact population of cell bodies to the left of the arrow for each cell body region depicted; locus ceruleus (LC), substantia nigra pars compacta (SNc), and ventral tegmental area (VTA). As loss of these neurons begins at the early (and likely prodromal) stages of the disease (depicted in color by transition between green and red in the Parkinson's progression arrow), progressively less neurotransmitter (norepinephrine (NE) and dopamine (DA)) is released in the targeted cortical (prefrontal (PFC) and orbitofrontal $(\mathrm{OFC})$ ) and subcortical (caudate, putamen, amygdala (AMY), and nucleus accumbens (NAc)) regions. In turn, these deficits in NE and DA release lead to deficits in EF, including decreased ability to inhibit choices that lead to disadvantageous outcomes, impaired attention to relevant stimuli associated with advantageous outcomes, impairment in recognizing reward saliency, and perseveration in decision-making that leads to disadvantageous outcomes.

patients who may be at-risk for therapeutic noncompliance.

However, we might infer the utility of the IGT in this capacity from the currently available data from 17 clinical PD studies. Of these, the study designs, the patient disease longevity and severity were varied. Thus, it would be logical to presume a varying degree of DA and NE loss in these patients, as well as varying amount or type of DRT. These factors make it difficult to interpret what an IGT outcome would mean for gauging therapeutic compliance. However, it would be inferred that the greater the disease severity the greater likelihood of catecholamine deficiency and therefore decreased IGT performance. Table 1 illustrates that the use of the IGT in PD patients currently shows inconsistent outcomes regarding performance, which may be related to the aforementioned issue of controlling for disease longevity and severity. The majority of these studies investigated patients with a PD diagnosis ranging from 3-15-years (mean $=7.6$ years) and stages ranging from de novo Stage 1 to stage 4.5 [60, 63-78]. Thus, it is likely that cortical loss of NE or DA innervation may be well-advanced. The neurobiological evidence presented earlier suggests that too little DA or NE in the cortical regions would conceivably impair strategic decision-making.

Of the 17 studies we reviewed, ten studies (two with DBS in the studies) reported that PD patients in the ON DRT state still performed worse than healthy controls [63, 67, 70-78] and one study showed a trend toward significantly worse scores [66]. Therefore, on the assumption that therapeutic non-compliance would be present in these patients (a current unknown), this would support that deficient catecholamine levels were present despite DRT being on-board. However, we also found three stud- 


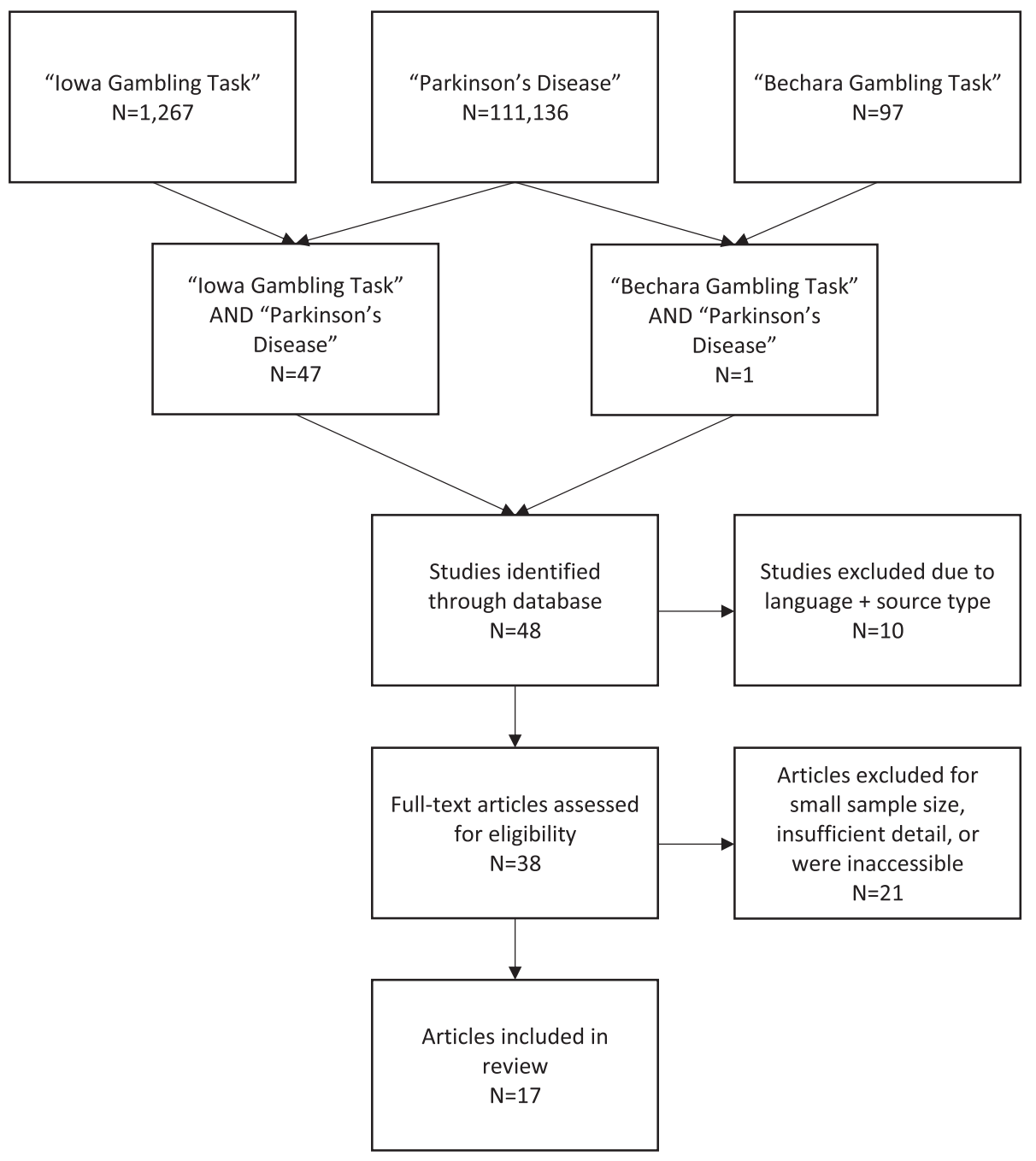

Fig. 2. Flow Diagram of Literature Search.

ies reporting no significant differences between PD patients in the ON DRT state and healthy controls $[65,68,69]$. This may suggest that the DRT therapy could have elevated DA levels sufficiently enough to mitigate non-strategic decision-making. If these studies did evaluate under OFF DRT, and found difference between control and PD, this would further support that deficient catecholamine signaling contributes to non-strategic decision-making. Finally, one study compared two PD groups with and without impulse control disorder and found no IGT differences, suggesting that a tendency toward nonstrategic decision-making may be inherent in PD patients, notably the patients in this study were faradvanced in years post-diagnosis [60]. One study compared DBS to non DBS and healthy controls and found the non-DBS PD groups in the ON DRT state performed comparably to healthy controls [63] and specific OFF DRT results were unclear. One study examined de novo PD patients and found no significant differences with healthy controls [64]. We argue a cross-over design comparing IGT performance in the ON and OFF DRT states would further support the hypothesized contribution of decreased catecholamine signaling in the cortical regions in IGT performance. Three of the studies that found significant differences between PD patients and healthy controls had a crossover design so that decisionmaking in patients in the ON and OFF DRT states could be examined $[63,67,70]$. One study showed that patients in OFF DRT performed worse than ON DRT [70]. 
Table 1

Clinical Investigations of the IGT Used in PD Patients on DRT Except One De Novo Study (Poletti et al.)

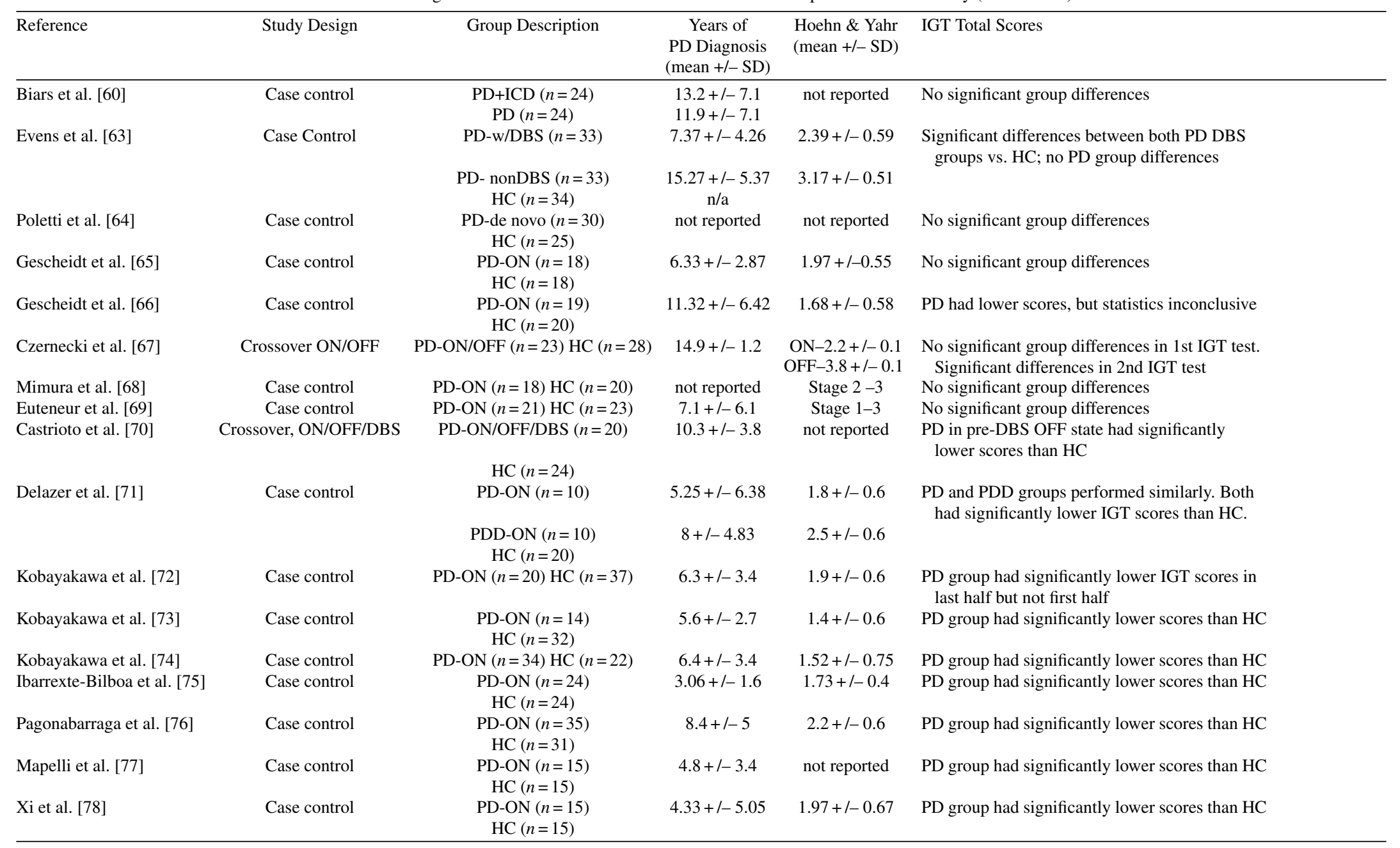

PD, Parkinson's disease; HC, Healthy Control; PDD, Parkinson's disease with dementia; ICD, impulse control disorder; DRT+, dopamine replacement therapy+concomittant meds; DBS, deep brain stimulation. 
The neurobiological evidence suggests that decreased cognitive flexibility and increased disinhibition are the most likely contributors promoting decisions to self-discontinue prescribed medications as a function of catecholamine imbalances and neuronal loss in key brain areas associated with EF. To illustrate, Fig. 1, shows the how the progressive neuropathology in PD may decrease response inhibition leading to cognitive inflexibility and non-strategic decision-making. Studies specifically designed to investigate therapeutic compliance and IGT performance among PD patients in the ON vs. OFF states vs. healthy controls in combination with samples of peripheral catecholamine biomarkers would arguably provide a clearer picture of the relationship between decisional capacity, catecholamine function, and therapeutic compliance. As it stands now, it is impossible to infer the potential for therapeutic compliance or non-compliance with the available data from these clinical trials. The findings that patients ON DRT still results in worse performance on the IGT compared to healthy controls indicate two possibilities: 1) that DA deficiencies in cortical regions may be too severe to be replenished to extent to improve strategic-decision making, or 2) deficient NE signaling in PD may be a stronger driving mechanism of impaired decision-making than previously realized.

Thus, it is important to re-examine Fig. 1 and the preclinical and translational data in relation to imaging studies in PD patients undergoing the IGT. Particularly, Kobayakawa et al. (2017) [72] captured brain region activation during the IGT in PD patients in comparison to healthy controls and found lateral and medial orbitofrontal atrophy that significantly correlated with non-strategic decision-making in the PD group. Moreover, imaging research has shown reduced volume, function, and activation in these brain areas are associated with disinhibition which may suggest the use of the IGT to identify problematic and disadvantageous decision-making in PD populations $[65,72,79]$.

As previously discussed, both DA and NE work hand-in-hand towards regulating reward-perception, response inhibition, and cognitive flexibility in particular brain areas that are associated with increased spontaneity and careless decision-making. These characteristics have strong potential to influence medication non-compliance. To this point, baseline IGT net total scores have been shown to predict future substance relapse in non-PD populations [24, 80-81]. Importantly, Stevens et al. (2014) [82] found that the IGT predicted patients who dropped out of treat- ment prematurely. Both Nejtek et al. (2013) [24] and Stevens et al. (2014) [82] found that patients who either relapsed or dropped out of treatment were unable to learn to inhibit disadvantageous decisions on the IGT, even after multiple test administrations at different time points.

Given the evidence that a single assessment using the IGT can predict relapse and treatment compliance in other patient populations, this test may have potential to identify individuals who might be prone to spontaneously self-discontinue their medications. We argue more controlled studies that evaluate IGT performance in the ON and OFF states will help strengthen the premise that a certain deficiency in cortical catecholamine levels may predict the likelihood of therapeutic non-compliance in the PD patient. Thus, more work is also warranted to examine cognitive characteristics in preclinical, prodromal PD, and PD patients to identify those who may be at-risk for therapeutic non-compliance. The little available clinical data examining the use of the IGT in PD populations provides a glimpse of its possible utility. Prospective studies that control for disease duration, disease severity, and DRT therapy levels, and possibly include cortical catecholamine image analysis would go a long way to help advance our knowledge to ascertain decision-making correlates medication response and compliance.

\section{DO MEN AND WOMEN WITH PD PERFORM THE IGT DIFFERENTLY?}

The prevalence and incidence of PD is approximately two-fold higher in men than women with women diagnosed at older ages than men [83-86]. In the early stages of PD, sex differences in PD motor symptom phenotype include men more often presenting with bradykinesia while tremors and postural instability are generally observed in women [86-88]. While sex differences in PD motor symptomatology are known, the influence of sex on executive functioning is understudied. However, since the seminal work of Maccoby and Jacklin [89], it is well-documented in healthy populations across the lifespan that females have better verbal memory, faster psychomotor and processing speed than males; and males have better visuospatial memory, spatial recognition, and mental rotation than females [90-92]. The same EF differences hold true for women and men with PD. The available data suggests that women with PD have better verbal memory 
[86], executive and global cognitive functioning than men [93-98]. Conversely, men with PD have better visuospatial memory than women [93, 99-103]. Data suggest that women learn verbal lists faster, have more efficient frontostriatal DA regulation, and higher DA receptor expression in the striatum that may be associated with higher estrogen levels [86, 104]. The intersection of catecholamines and estrogen in PD patients presents an interesting perspective in possibly explaining the sex differences in decisionmaking in the PD population [100, 104-109].

Although non-strategic decision-making is more common in men with PD than in women [11, 109-112], both sexes may exhibit risk-taking behaviors (e.g., pathological gambling, compulsive buying, etc.) while temporal discounting (e.g., inability to delay gratification) is more associated with men than women [6, 11, 109-111, 113]. In PD populations, although both sexes may exhibit some non-strategic decision-making [77, 78, 113], there remains a need to determine the extent to which this cognitive domain influences clinical outcomes in men compared to women. The general consensus in healthy adult populations performing the IGT is that men learn the strategy of choosing advantageous cards quicker than women, but over time women catch up to the strategy and the end net result is the same for both sexes [114-116]. Thus, performance on the IGT in the PD population may not be uniquely reflective of PD as overall sex differences in cognitive functioning exists even in healthy controls.

To our knowledge, there are no studies specifically examining sex differences in IGT performance in patients with PD in relation to advancing a clinical perspective for sex-specific therapeutic compliance. In contrast, some data suggests that women with PD may have latent complications associated with DA therapy [116] that may influence careless decisionmaking. However, it is currently not possible to determine the clinical applicability of IGT performance in relation to predicting the apparent sex differences found in PD. Although men with PD may have a higher risk for making non-strategic decisions than women, it is unclear whether or not this translates into men having more problems with therapeutic compliance and disease resiliency.

\section{INTEGRATING THE FINDINGS}

It is evident that many PD patients will have decision-making problems during the course of their illness. Non-strategic decision-making may be applied to therapeutic complications associated with medication non-compliance leading to poor health trajectories overall. As there are emerging reliable physiological, image-based, and genetic biomarkers associated with predicting risks for prodromal and early stage PD $[117,118]$, the IGT may be a useful companion to detect non-strategic decision-making already on-board prior to motor impairment. Of the phenotypic markers related to prodromal $\mathrm{PD}$, the most well-documented and conclusive markers of prodromal PD is REM sleep behavior disorder (RBD) $[117,118]$. Given the emphasis on RBD as a predictive marker of prodromal PD, we found one study that that described IGT outcomes in RBD patients that might provide a rationale for examining the IGT's applicability in PD.

In a non-PD sample, Delazer et al. (2012) [119] used a neuropsychological battery measuring various domains of EF in RBD patients compared to healthy age- and education-matched controls to exclude cognitive impairment in their sample. The researchers then used the IGT to specifically measure non-strategic decision-making, the Information Sampling Task, Intra/Extra Dimensional Shift task, One Touch Stockings of Cambridge (similar to Tower of London), and the Go-NoGo Task to measure cognitive impulsivity and complex problem solving. The outcomes of this study showed that only the IGT revealed significant group differences in RBD compared to age-matched controls, as RBD patients made significantly more non-strategic, disadvantageous decisions. This study indicates that the IGT may identify subtle cognitive problems by interrogating strategy-based decisional capacity in PD patients that might not otherwise be revealed with other types of neuropsychological tests specifically designed to diagnose cognitive impairment. For example, many of the neuropsychological tests require adequately intact motor functioning (e.g., Trail-making Tests A and B, Rey Osterrieth Complex Figure Test, Block design, Bells Test, etc.) while others depend on visual color accuracy (e.g., Wisconsin Card Sorting Task, Stroop Color Word Test, etc.). As a computerized test that does not depend on visuospatial capabilities nor color accuracy, the IGT may be a viable alternative assessment tool especially when decision-making is of particular interest.

The most recent and interesting data elucidating decisional capacity in PD suggests that there is significant loss of noradrenergic functions from the LC and DA loss from the SN impacting its connection to 
the PFC. This new finding of the SN-PFC connection expands the traditional view of the roles DA and VTA alone may have played in EF and decision-making in PD populations. Now, accumulating evidence is pointing towards a combined contribution of $\mathrm{LC}$ and $\mathrm{NE}$ with nigrostriatal and mesolimbic DA signaling in the OFC and PFC that are critically important neural factors underlying cognitive flexibility and response inhibition necessary for strategic decision-making.

The significant relationships among cognitive and motor functioning, therapeutic compliance, and disease resilience present a clinically challenging rationale for using the IGT to assess decision-making prior to global cognitive or motor decline. However, in the absence of frank cognitive and motor impairment, the IGT may have the potential to evaluate an individual's capacity to make strategic decisions prior to a firm PD diagnosis. Particularly relevant to PD patients is the high mortality rate associated with therapeutic non-compliance with complex DA treatment regimens that depends on a patients' ability to make strategic decisions while inhibiting impulses to self-discontinue or adjust their medication regimen. Although more research is needed, when all other domains of cognitive functioning are intact, the IGT may help identify subtle, non-strategic decisionmaking in those at-risk for preclinical or prodromal $\mathrm{PD}$ and therapeutic non-compliance.

\section{CONCLUSION}

Evidence of impairments to catecholamine function can be interrogated at multiple levels, including CNS-imaging and serum analysis. These biomarkers, if seen in conjunction with subtle cognitive impairments seen in premotor and early-stage PD or with other indicators of compromised peripheral functions such as dysautomnia [120], would increase the likelihood of detecting PD pathology or identify the clinical issue facing the PD patient, which as we discussed, include therapeutic non-compliance. As such, the IGT is argued to be a useful companion in this regard.

This review presents the currently available data from animal models and human studies investigating the neurobiology of EF in PD and the applicability of the IGT to reveal decisional capacity associated with the neural areas, pathways, and/or catecholamine dysfunction underlying PD neuropathology. Using the IGT to identify potential problems with therapeutic compliance due to the high rate of mortality in PD resulting from decisions to self-discontinue or self-adjust DRT is worthy of future research. We also found that the available data indicates that the IGT interrogates the same neural areas involved in PD neuropathology. Here, we have summarized the available data that may point researchers toward a more unified approach concerning the applicability of using the IGT in PD, towards identifying risks for preclinical or prodromal PD (if used alongside other well-established markers), and therapeutic noncompliance. However, the IGT may not differentiate or predict decisional capacity in men versus women with PD.

\section{ACKNOWLEDGMENTS}

This research did not receive any specific grant from funding agencies in the public, commercial, or not-for-profit sectors.

\section{CONFLICT OF INTEREST}

The authors have no conflicts of interest to report.

\section{REFERENCES}

[1] Marras C, Beck J, Bower, Roberts E, Ritz B, Ross GW, Abbott RD, Savica R, Van Den Edden SK, Willis AW, Tanner CM (2018) Prevalence of Parkinson's disease in North America. Nature 4, 21.

[2] Chaudhuri K, Odin P, Antonini A, Martinez-Martine P (2011) Parkinson's disease: The non-motor issues. Parkinsonism Relat Disord 17, 717-723.

[3] Goldman JG, Vernaleo BA, Camicioli R, Dahodwala N, Dobkin RD, Ellis T, Galvin JE, Marras C, Edwards J, Fileds J, Golden R, Karlawish J, Levin B, Shulman L, Smith G, Tangney C, Thomas CA, Troster AI, Uc EY, Coyan N, Ellman C, Ellman M, Hoffman C, Hoffman S, Simmonds D (2018) Cognitive impairment in Parkinson's disease: A report from a multidisciplinary symposium on unmet needs and future directions to maintain cognitive health. NPJ Parkinsons Dis 4, 19.

[4] Fengler S, Liepelt-Scarfone I, Brockmann K, Schaffer E, Berg D, and Kalbe E (2017) Cognitive changes in prodromal Parkinson's disease: A review. Mov Disord 32, 1655-1666.

[5] Durcan R, Wiblin L, Lawson RA, Khoo TK, Yarnall AJ, Duncan GW, Brooks DJ, Pavese N, Burn DJ, ICICLE-PD Study Group (2019) Prevalence and duration of non-motor symptoms in prodromal Parkinson's disease. Eur J Neurol 26, 979-985.

[6] Antonini A, Barone P, Bonuccelli U, Annoni K, Asgharnejad M, Stanzione P (2017) ICARUS study: Prevalence and clinical features of impulse control disorders in Parkinson's disease. J Neurol Neurosurg Psychiatry 88, 317-324.

[7] Maloney EM, Djamshidian A, O'Sullivan SS (2017) Phenomenology and epidemiology of impulsive-compulsive 
behaviours in Parkinson's disease, atypical Parkinsonian disorders and non-Parkinsonian populations. J Neurol Sci 374, 47-52.

[8] Martini A, Weis L, Fiorenzato E, Schifano R, Cianci V, Antonini A, Biundo R (2019) Impact of cognitive profile on impulse control disorders presence and severity in Parkinson's disease. Front Neurol 10, 266.

[9] Eisinger RS, Ramierez-Zamora A, Carbunaru S, Ptak B, Peng-Chen Z, Okun MS, Gunduz A (2019) Medications, deep brain stimulation, and other factors influencing impulse control disorders in Parkinson's disease. Front Neurol 10, 86.

[10] Molde H, Moussavi Y, Kopperud ST, Erga AH, Hansen AL, Pallesen S (2018) Impulse-control disorders in Parkinson's disease: A meta-analysis and review of case-control studies. Front Neurol 9, 330.

[11] Nombela C, Rittman T, Robbins TW, Rowe JB (2014) Multiple modes of impulsivity in Parkinson's disease. PLoS One 9, e85747.

[12] Straka I, Minar M, Skorvanek M, Grofik M, Danterova K, Benetin J, Kurca E, Gazova A, Bolekova V, Wyman-Chick KA, Kyselovic J, Valkovic P (2019) Adherence to pharmacotherapy in patients with Parkinson's disease taking three and more daily doses of medication. Front Neurol 10, 799.

[13] Robottom B, Gruber-Baldini A, Anderson K, Reich S, Fishman P, Weiner W, Shulman LM (2012) What determines resilience in patients with Parkinson's disease? Parkinsonism Relat Disord 18, 174-177.

[14] Brugger F, Abela E, Hägele-Link S, Bohlhalter S, Galovic M, Kägi G (2015) Do executive dysfunction and freezing of gait in Parkinson's disease share the same neuroanatomical correlates? J Neurol Sci 356, 184-187.

[15] Wang YX, Zhao J, Li DK, Peng F, Wang Y, Yang K, Liu ZY, Liu FT, Wu JJ, Wang J (2017) Associations between cognitive impairment and motor dysfunction in Parkinson's disease. Brain Behav 7, e00719.

[16] Bechara A, Damasio AR, Damasio H, Anderson S (1994) Insensitivity to future consequences following damage to human prefrontal cortex. Cognition 50, 7-15.

[17] Bechara A, Damasio H, Tranel D, Damasio AR (1997) Deciding advantageously before knowing the advantageous strategy. Science 275, 1293-1295.

[18] Bechara A, Damasio H, Tranel D, Anderson SW (1998) Dissociation of working memory from decision making within the human prefrontal cortex. J Neurosci 18, 428-437.

[19] Bechara A, Damasio H, Damasio AR, Lee GP (1999) Different contributions of the human amygdala and ventromedial prefrontal cortex to decision-making. J Neurosci 19, 5473-5481.

[20] Bechara A, Tranel D, Damasio H, Damasio AR (2000) Characterization of the decision-making deficit of patients with ventromedial prefrontal cortex lesions. Brain 123, 2189-2202.

[21] Bechara A, Damasio H, Damasio AR (2000) Emotion, decision-making and the orbitofrontal cortex. Cereb Cortex 10, 295-307.

[22] Bechara A, Damasio H, Tranel D, Damasio AR (2005) The Iowa Gambling Task and the somatic marker hypothesis: Some questions and answers. Trends Cogn Sci 9, 159-162.

[23] Damasio A, Tranel D, Damasio H (1991) Somatic markers and the guidance of behavior: Theory and preliminary testing. In Frontal Lobe Function and Dysfunction, Levin
HS, Eisenberg HM, Benton AL, eds. Oxford University Press, New York, pp. 217-229.

[24] Nejtek VA, Kaiser KA, Zhang B, Djokovic M (2013) Iowa Gambling Task scores predict future drug use in bipolar disorder outpatients with stimulant dependence. Psychiatry Res 210, 871-879.

[25] MacDonald PA, MacDonald A.A, Seergobin KN, Tamjeedi R, Ganjavi H, Provost JS, Monchi O (2011) The effect of dopamine therapy on ventral and dorsal striatummediated cognition in Parkinson's disease: Support from functional MRI. Brain 134, 1447-1463.

[26] Grospe GM, Baker PM, Ragozzino ME (2018) Cognitive flexibility deficits following 6-OHDA lesions of the rat dorsomedial striatum. Neuroscience 374, 80-90.

[27] Sara SJ (2009) The locus coeruleus and noradrenergic modulation of cognition. Nat Neurosci 10, 211-223.

[28] Cerpa JC, Marchand AR, Coutureau E (2019) Distinct regional patterns in noradrenergic innervation of the rat prefrontal cortex. J Chem Neuroanat 96, 102-109.

[29] Ishii H, Ohara S, Tobler PN, Tsutsui KI, Iijima T (2015) Dopaminergic and serotonergic modulation of anterior insular and oribitofrontal cortex function in risky decision making. Neurosci Res 92, 53-61.

[30] Orsini CA, Moorman DE, Young JW, Setlow B, Floresco SB (2015) Neural mechanisms regulating different forms of risk-related decision-making: Insights from animal models. Neurosci Biobehav Rev 58, 147-167.

[31] Wise RA. (2009) Role for nigrostriatal-not just mesocorticolimbic-dopamine in reward and addiction. Trends Neurosci 32, 517-524.

[32] Weinshenker D (2018) Long road to ruin: Noradrenergic dysfunction in neurodegenerative disease. Trends $\mathrm{Neu}$ rosci 41, 211-223.

[33] Seip-Cammack KM, Young JJ, Young ME, Shapiro ML (2017) Partial lesion of the nigrostriatal dopamine pathway in rats impairs egocentric learning but not spatial learning or behavioral flexibility. Behav Neurosci 131, 135-142.

[34] Seamans JK, Yang CR. (2004) The principal features and mechanisms of dopamine modulation in the prefrontal cortex. Prog Neurobiol 74, 1-57.

[35] Ott T, Nieder A (2019) Dopamine and cognitive control in prefrontal cortex. Trends Cogn Sci 23, 213-234.

[36] Matsumoto M, Takada M (2013) Distinct representations of cognitive and motivational signals in midbrain dopamine neurons. Neuron 5, 1011-1024.

[37] Borodovitsyna O, Flamini M, Chandler D (2017) Noradrenergic modulation of cognition in health and disease. Neural Plast 2017, 6031478.

[38] Chamberlain SR, Robbins TW (2013) Noradrenergic modulation of cognition: Therapeutic implications. J Psychopharmacol 27, 694-718.

[39] Buddhala C, Loftin SK, Kuley BM, Cairns NJ, Campbell MC, Perlmutter JS, Kotzbauer PT (2015) Dopaminergic, serotonergic, and noradrenergic deficits in Parkinson disease. Ann Clin Transl Neurol 2, 949-959.

[40] Giguere N, Burke Nanni S, Trudeau LE (2018) On cell loss and selective vulnerability of neuronal populations in Parkinson's disease. Front Neurol 9, 455.

[41] Enkhuizen J, Geyer MA, Young JW (2013) Differential effects of dopamine transporter inhibitors in the rodent Iowa gambling task. Psychopharmacology 225, 661-674.

[42] Cabeza L, Giustiniani J, Chabin T, Ramadan B, Joucia C, Nicolier M, Pazart L, Haffen E, Fellman D, Gabriel D, Peterschmitt Y (2020) Modelling decision-making under uncertainty: A direct comparison study between human 
and mouse gambling data. Eur Neuropsychopharmacol 31, 58-68.

[43] Kordower JH, Olanow CW, Dodiya HB, Chu Y, Beach TG, Adler CH, Halliday GM, Bartus RT (2013) Disease duration and the integrity of the nigrostriatal system in Parkinson's disease. Brain 136, 2419-2428.

[44] Bezard E, Dovero S, Prunier C, Ravenscroft P, Chalon S, Guilloteau D, Crossman AR, Bioulac B, Brotchie JM, Gross CE (2001) Relationship between the appearance of symptoms and the level of nigrostriatal degeneration in a progressive 1-methyl-4-phenyl-1,2,3,6tetrahydropyridine- lesioned Macaque model of Parkinson's disease. J Neurosci 21, 6853-6861.

[45] Salvatore MF, Terrebonne J, Cantu MA, McInnis TR, Venable K, Kelley P, Kasanga EA, Latimer B, Owens CL, Pruett BS, Yu Y, Luedtke R, Forster MJ, Sumien N, Ingram DK (2017) Dissociation of striatal dopamine and tyrosine hydroxylase expression from aging-related motor decline: Evidence from calorie restriction intervention. J Gerontol A Biol Sci Med Sci 73, 11-20.

[46] Alberico SL, Cassell MD, Narayanan NS (2015) The vulnerable ventral tegmental area in Parkinson's disease. Basal Ganglia 5, 51-55.

[47] Caminiti SP, Presotto L, Baroncini D, Garibotto V, Moresco RM, Gianolli L, Volonte MA, Antonini A, Perani D (2017) Axonal damage and loss of connectivity in nigrostriatal and mesolimbic dopamine pathways in early Parkinson's disease. Neuroimage Clin 14, 734-740.

[48] Tennyson SS, Brockett AT, Hricz NW, Bryden DW, Roesch MR (2018) Firing of putative dopamine neurons in ventral tegmental area is modulated by probability of success during performance of a stop-change task. eNeuro 5, ENEURO.0007-18.2018.

[49] Chandler DJ, Jensen P, McCall JG, Pickering AE, Schwarz LA, Toth NK (2019) Redefining noradrenergic neuromodulation of behavior: Impacts of a modular locus coeruleus architecture. J Neurosci 39, 8239-8249.

[50] Li Y, Wang C, Wang J, Zhou Y, Ye F, Zhang Y, Cheng X, Huang Z, Liu K, Guoqiang F, Zhong C, Zeng M, Jin L (2019) Mild cognitive impairment in de novo Parkinson's Disease: A neuromelanin MRI study in locus coeruleus. Mov Disord 34, 884-892.

[51] Oertel WH, Henrich MT, Jansen A, Geibi FF (2019) The locus ceruleus: Another vulnerability target in Parkinson's disease. Mov Disord 34, 1423-1429.

[52] Matuskey D, Tinaz S, Wilcox KC, Naganawa M, Toyonaga T, Dias M, Henry S, Pittman B, Ropchan J, Nabulsi N, Suridjan I, Comley RA, Huang Y, Finnema SJ, Carson RE (2020) Synaptic changes in Parkinson's disease assessed with in-vivo imaging. Ann Neurol 87, 329-338.

[53] Masilamoni GJ, Groover O, Smith Y (2017) Reduced noradrenergic innervation of ventral midbrain dopaminergic cell groups and the subthalamic nucleus in MPTP-treated parkinsonian monkeys. Neurobiol Dis 100, 9-18.

[54] Bjerken S, Persson RS, Barkander A, Karalija N, Pelegrina-Hidalgo N, Gerhardt GA, Virel A, Strömberg I (2019) Noradrenaline is crucial for the substantia nigra dopaminergic cell maintenance. Neurochem Int 131, 104551.

[55] Vazey EM, Aston-Jones G (2012) The emerging role of norepinephrine in cognitive dysfunctions of Parkinson's disease. Front Behav Neurosci 6, 48.

[56] Carli M, Robbins TW, Evenden JL, Everitt BJ (1983) Effects of lesions to ascending noradrenergic neurones on performance of a 5-choice serial reaction task in rats; implications for theories of dorsal noradrenergic bundle function based on selective attention and arousal. Behav Brain Res 9, 361-380.

[57] Bradshaw SE, Agster KL, Waterhouse BD, McGaughy JA (2016) Age-related changes in prefrontal norepinephrine transporter density: The basis for improved cognitive flexibility after low doses of atomoxetine in adolescent rats. Brain Res 1641, 245-257.

[58] Reynaud AJ, Froesel M, Guedj C, Ben Hadj Hassen S, Clery J, Meunier M, Ben Hamed S, Hadj-Bouziane F (2019) Atomoxetine improves attentional orienting in a predictive context. Neuropharmacology 150, 59-69.

[59] Rae CL, Nombela C, Rodriguez PV, Ye Z, Hughes LE, Jones PS, Ham T, Rittman T, Coyle-Gilchrist I, Regenthal R, Sahakian BJ, Barker RA, Robbins TW, Rowe JB (2016) Atomoxetine restores the response inhibition network in Parkinson's disease. Brain 139, 2235-2248.

[60] Biars J, Johnson N, Nespeca M, Busch R, Kubu C, Floden D (2019) Iowa Gambling Task performance in Parkinson disease patients with impulse control disorders. Arch Clin Neuropsychol 34, 310-318.

[61] Daley DJ, Myint PK, Gray RJ, Deane KHO (2012) Systematic review on factors associated with medication non-adherence in Parkinson's disease. Parkinsonism Relat Disord 18, 1053-1061.

[62] Newman EJ, Grosset DG, Kennedy PGE (2009). The Parkinsonism-Hyperpyrexia Syndrome. Neurocrit Care 10, 136-140.

[63] Evens R, Stankevich Y, Dshemuchadse M, Storch A, Wolz M, Reichmann H, Schlaepfer TE, Goschke T, Lueken U (2016) The impact of Parkinson's disease and subthalamic deep brain stimulation on reward processing. Neuropsychologia 75, 11-19.

[64] Poletti M, Frosini D, Lucetti C, Del Dotto P, Ceravolo $\mathrm{R}$, Bonuccelli U (2012) Iowa gambling task in de novo Parkinson's disease: A comparison between good and poor performers. Mov Disord 27, 330-332.

[65] Geshceidt T, Marecek R, Mikl M, Czekoova K, Urbanek T, Vanicek J, Shaw DJ, Bares M (2013) Functional anatomy of outcome evaluation during Iowa gambling task performance in patients with Parkinson's disease: An fMRI study. Neurol Sci 34, 2159-2166.

[66] Gescheidt T, Czekoova K, Urbanek T, Marecek R, Mikl M, Kubikova R, Telecka S, Andrlova H, Husarova I, Bares M (2012) Iowa gambling task in patients with earlyonset Parkinson's disease: Strategy analysis. Neurol Sci 33, 1329-1335.

[67] Czernecki V, Pillon B, Houeto JL, Pochon JB, Levy R, Dubois B (2002) Motivation, reward, and Parkinson's disease: Influence of dopatherapy. Neuropsychologia 40, 2257-2267.

[68] Mimura M, Oeda R, Kawamura M (2006) Impaired decision-making in Parkinson's disease. Parkinsonism Relat Disord 12, 169-175.

[69] Euteneuer F, Schaefer F, Stuermer R, Boucsein W, Timmermann L, Barbe MT, Ebersbach G, Otto J, Kessler J, Kalbe E (2009) Dissociation of decision-making under ambiguity and decision-making under risk in patients with Parkinson's disease: A neuropsychological and psychophysiological study. Neuropsycholigia 47, 2882-2890.

[70] Castrioto A, Funkiewiez A, Debu B, Cools R, Lhommee E, Ardouin C, Fraix V, Chabardes S, Robbins TW, Pollak P, Krack P (2014) Iowa gambling task impairment in Parkinson's disease can be normalized by reduction of 
dopaminergic medication after subthalamic stimulation. $J$ Neurol Neurosurg Psychiatry 86, 186-190.

[71] Delazer M, Sinz H, Zamarian L, Stockener H, Seppi K, Wenning GK, Benke T, Poewe W (2009) Decision making under risk and under ambiguity in Parkinson's disease. Neuropsycholigia 47, 1901-1908.

[72] Kobayakawa M, Tsuruya N, Kawamura M (2017) Decision-making performance in Parkinson's disease correlated with lateral orbitofrontal volume. J Neurolog Sci 372, 232-238.

[73] Kobayakawa M, Tsuruya N, Kawamura M (2010) Sensitivity to reward and punishment in Parkinson's disease: An analysis of behavioral patterns using a modified version of the Iowa gambling task. Parkinsonism Relat Disord 16, 453-457.

[74] Kobayakawa M, Shinichi K, Mimura M, Kawamura M (2008) Decision making in Parkinson's disease: Analysis of behavioral and physiological patterns in Iowa gambling task. Mov Disord 23, 547-552.

[75] Ibarrexte-Bilboa N, Junque C, Tolosa E, Marti MJ, Valldeoriola F, Bargallo N, Zarei M (2009) Neuroanatomical correlates of impaired decision-making and facial emotion recognition in early Parkinson's disease. Eur J Neurosci 30, 1162-1171.

[76] Pagonabarraga J, Garcia-Sanchez C, Llebaria G, PascualSedano B, Gironell A, Kulisevsky J (2007) Controlled study of decision-making and cognitive impairment in Parkinson's disease. Mov Disord 22, 1430-1415.

[77] Mapelli D, Di Rosa E, Cavalletti M, Schiff S, Tamburin S (2014) Decision and dopaminergic system: An ERPs study of Iowa gambling task in Parkinson's disease. Front Psychol 5, 684.

[78] Xi C, Zhu Y, Mu Y, Chen B, Dong B, Cheng H, Hu P, Zhu C, Wang K (2015) Theory of mind and decisionsmaking processes are impaired in Parkinson's disease. Behav Brain Res 279, 226-233.

[79] Geshceidt T, Marecek R, Mikl M, Czekoova K, Urbanek T, Vanicek J, Shaw DJ, Bares M (2013) Functional anatomy of outcome evaluation during Iowa gambling task performance in patients with Parkinson's disease: An fMRI study. Neurol Sci 34, 2159-2166.

[80] DeWilde B, Verdejo-Garcia A, Sabbe B, Hulstijn W, Dom $\mathrm{G}$ (2013) Affective decision-making is predictive of threemonth relapse in polysubstance-dependent alcoholics. Eur Addict Res 19, 21-28.

[81] Verdejo-Garcia A, Albein-Urios N, Martinez-Gonzalez JM, Civit E, de la Torre R, Lozano O (2014). Decisionmaking impairment predicts 3-month hair-indexed cocaine relapse. Psychopharmacology 231, 4179-4187.

[82] Stevens L, Betanzos-Espinosa P, Crunelle C, VergaraMoragues E, Roeyers H, Lozano O, Dom G, GonzalezSaiz F, Vanderplasschen W, Verdejo-García A, PérezGarcía M (2013) Disadvantageous decision-making as a predictor of drop-out among cocaine-dependent individuals in long-term residential treatment. Front Psychiatry 4, 149 .

[83] Baldereschi M, Di Carlo A, Rocca WA, Vanni P, Maggi S, Perissinotto E, Grigoletto F, Amaducci L, Inzitari D (2000) Parkinson's disease and parkinsonism in a longitudinal study: Two-fold higher incidence in men. ILSA Working Group. Italian Longitudinal Study on Aging. Neurology 55, 1358-1363.

[84] Elbaz A, Peterson BJ, Yang P, Van Gerpen JA, Bower JH, Maraganore DM, Mcdonnell SK, Ahlskog JE, Rocca WA
(2002) Nonfatal cancer preceding Parkinson's disease: A case-control study. Epidemiology 13, 157-164.

[85] Van Den Eeden SK, Tanner CM, Bernstein AL, Fross RD, Leimpeter A, Bloch DA, Nelson LM (2003) Incidence of Parkinson's disease: Variation by age, gender, and race/ethnicity. Am J Epidemiol 157, 1015-1022.

[86] Haaxma CA, Bloem BR, Borm GF, Oyen WJ, Leenders KL, Eshuis S, Booij J, Dluzen DE, Horstink MW (2007) Gender differences in Parkinson's disease. J Neurol Neurosurg Psychiatry 78, 819-824.

[87] Hariz GM, Lindberg M, Hariz MI, Bergenheim AT (2003) Gender differences in disability and health-related quality of life in patients with Parkinson's disease treated with stereotactic surgery. Acta Neurol Scand 108, 28-37.

[88] Baba Y, Putzke JD, Whaley NR, Wszolek ZK, Uitti RJ (2005) Gender and the Parkinson's disease phenotype. $J$ Neurol 252, 1201-1205.

[89] Maccoby EE, Jacklin CN (1974) The psychology of sex differences. Stanford University Press, MD.

[90] Lezak MD, Howieson DB, Loring DW, Hannay HJ, Fischer JS (2004) Neuropsychological assessment, 4th Ed. Oxford University Press.

[91] Andreano JM, Cahill L (2009) Sex influences on the neurobiology of learning and memory. Learn Mem 16, 248-266.

[92] Voyer D, Voyer SD, Saint-Aubin J (2017) Sex differences in visual-spatial working memory: A meta-analysis. Psychon Bull Rev 24, 307-334.

[93] Locascio JJ, Corkin S, Growdon JH (2003) Relation between clinical characteristics of Parkinson's disease and cognitive decline. J Clin Exp Neuropsychol 25, 94-109.

[94] Foltynie T, Lewis SG, Goldberg TE, Blackwell AD, Kolachana BS, Weinberger DR, Robbins TW, Barker RA (2005) The BDNF Val66Met polymorphism has a gender specific influence on planning ability in Parkinson's disease. J Neurol 252, 833-838.

[95] Heller J, Dogan I, Schulz JB, Reetz K (2013) Evidence for gender differences in cognition, emotion and quality of life in Parkinson's disease? Aging Dis 5, 63-75.

[96] Song Y, Gu Z, An J, Chan P, Chinese Parkinson Study Group (2014) Gender differences on motor and non-motor symptoms of de novo patients with early Parkinson's disease. Neurol Sci 35, 1991-1996.

[97] Augustine EF, Perez A, Dhall R, Umeh CC, Videnovic A, Cambi F, Wills AM, Elm JJ, Zweig RM, Shulman LM, Nance MA, Bainbridge, J, Suchowersky O (2015) Sex differences in clinical features of early, treated Parkinson's disease. PLoS One 10 7, e0133002.

[98] Gao L, Nie K, Tang H, Wang L, Zhao J, Gan R, Huang J, Feng S, Zhu R, Duan Z, Zhang Y, Wang L (2015) Sex differences in cognition among Chinese people with Parkinson's disease. J Clin Neurosci 22, 488-492.

[99] Liu R, Umbach DM, Peddada SD, Xu Z, Troste AI, Huang X, Chen H (2015) Potential sex differences in nonmotor symptoms in early drug-naive Parkinson disease. Neurology 84, 2107-2115.

[100] Miller IN, Cronin-Golomb A (2010) Gender differences in Parkinson's disease: Clinical characteristics and cognition. Mov Disord 25, 2695-2703.

[101] Agrell B, Dehlin O (2012) The clock-drawing test. 1998. Age Ageing 41(Suppl 3), iii41-45.

[102] Sundermann EE, Biegon A, Rubin LH, Lipton RB, Mowrey W, Landau S, Maki PM, Alzheimer's Disease Neuroimaging Initiative (2016) Better verbal memory in 
women than men in MCI despite similar levels of hippocampal atrophy. Neurology 86, 1368-1376.

[103] Sundermann EE, Maki PM, Rubin LH, Lipton RB, Landau S, Biegon A, Alzheimer's Disease Neuroimaging Initiative (2016) Female advantage in verbal memory: Evidence of sex-specific cognitive reserve. Neurology 87, 19161924.

[104] Mozley LH, Gur RC, Mozley PD, Gur RE (2001) Striatal dopamine transporters and cognitive functioning in healthy men and women. Am J Psychiatry 158, 14921499.

[105] Lavalaye J, Booij J, Reneman L, Habraken JB, Van Royen EA (2000) Effect of age and gender on dopamine transporter imaging with [123I]FP-CIT SPECT in healthy volunteers. Eur J Nucl Med 27, 867-869.

[106] Munro CA, Mccaul ME, Wong DF, Oswald LM, Zhou Y, Brasic J, Kuwabara H, Kumar A, Alexander M, Ye W, Wand GS (2006) Sex differences in striatal dopamine release in healthy adults. Biol Psychiatry 59, 966-974.

[107] Cereda E, Barichella M, Cassani E, Caccialanza R, Pezzoli G (2013) Reproductive factors and clinical features of Parkinson's disease. Parkinsonism Relat Disord 19, 10941099.

[108] Lv M, Zhang Y, Chen GC, Li G, Rui Y, Qin L, Wan Z (2017) Reproductive factors and risk of Parkinson's disease in women: A meta-analysis of observational studies. Behav Brain Res 335, 103-110.

[109] Ruitenberg MFL, Wu T, Averbeck BB, Chou KL, Koppelmans V, Seidler RD (2018) Impulsivity in Parkinson's disease is associated with alterations in affective and sensorimotor striatal networks. Front Neurol 9, 279-279.

[110] Weintraub D (2019) Impulse control disorders in Parkinson's disease: A 20-year odyssey. Mov Disord 34, 447-452.

[111] Weintraub D, Claassen DO (2017) Impulse control and related disorders in Parkinson's disease. Int Rev Neurobiol 133, 679-717.
[112] Callesen MB, Scheel-Kruger J, Kringelbach ML, Moller A (2013) A systematic review of impulse control disorders in Parkinson's disease. J Parkinsons Dis 3, 105-138.

[113] Milenkova M, Mohammadi B, Kollewe K, Schrader C, Fellbrich A, Wittfoth M, Dengler R, Münte TF (2011) Intertemporal choice in Parkinson's disease. Mov Disord 26, 2004-2010.

[114] Overman WH, Pierce A (2013) Iowa Gambling Task with non-clinical participants: Effects of using real+virtual cards and additional trials. Front Psychol 4, 935.

[115] Van Den Bos R, Homberg J, De Visser L (2013) A critical review of sex differences in decision-making tasks: Focus on the Iowa Gambling Task. Behav Brain Res 238, 95-108.

[116] Singh V (2016) Sex-differences, handedness, and lateralization in the Iowa Gambling Task. Front Psychol 7, 708.

[117] Postuma RB, Berg D (2019) Prodromal Parkinson's disease: The decade past, the decade to come. Mov Disord 34, 665- 675.

[118] Heinzel S, Berg D, Gasser T, Honglei C, Yao C, Postuma RB, MDS Task Force on the Definition of Parkinson's Disease (2019) Update of the MDS research criteria for prodromal Parkinson's disease. Mov Disord 34, 14641470.

[119] Delazer M, Hogl B, Zamarian L, Wenter J, Ehrmann L, Gschliesser V, Brandauer E, Werner P, Frauscher B (2012) Decision making and executive functions in REM sleep behavior disorder. Sleep 35, 667-673.

[120] Salvatore M, Disbrow EA, Emborg ME (2014) Periperal and cognitive signs: Delineating the significance of impaired catecholamine metabolism in Parkinson's disease progression. J Neurochem 131, 129-133. 